\title{
Plumbing and wiring: Atherosclerosis in epilepsy.
}

Scott Mintzer, MD

Thomas Jefferson University

Follow this and additional works at: https://jdc.jefferson.edu/neurologyfp

Part of the Neurology Commons

Let us know how access to this document benefits you

\section{Recommended Citation}

Mintzer, MD, Scott, "Plumbing and wiring: Atherosclerosis in epilepsy." (2014). Department of

Neurology Faculty Papers. Paper 78.

https://jdc.jefferson.edu/neurologyfp/78

This Article is brought to you for free and open access by the Jefferson Digital Commons. The Jefferson Digital Commons is a service of Thomas Jefferson University's Center for Teaching and Learning (CTL). The Commons is a showcase for Jefferson books and journals, peer-reviewed scholarly publications, unique historical collections from the University archives, and teaching tools. The Jefferson Digital Commons allows researchers and interested readers anywhere in the world to learn about and keep up to date with Jefferson scholarship. This article has been accepted for inclusion in Department of Neurology Faculty Papers by an authorized administrator of the Jefferson Digital Commons. For more information, please contact: JeffersonDigitalCommons@jefferson.edu. 
As submitted to:

Epilepsy \& Behavior: E\&B

And later published as:

Plumbing and Wiring: Atherosclerosis in Epilepsy

December 2014, Volume 41, pages: 274-5

DOI: $10.1016 /$ j.yebeh.2014.08.144

Scott Mintzer, MD

Department of Neurology Thomas Jefferson University 901 Walnut Street, 4th Floor Philadelphia, PA 19107

tel: $215-955-1222$

fax: 215-955-1055

scott.mintzer@jefferson.edu

Over the long term, epilepsy is clearly associated with cognitive impairment. This has been demonstrated functionally, using neuropsychological testing, and reinforced by structural studies showing progressive atrophy in patients with chronic epilepsy ${ }^{1-3}$. The prevailing explanation for this, of course, has been the direct and cumulative effects of seizures on the brain. The basic science literature is chock full of studies showing impairment of neuronal function after seizures, both acutely and chronically. And for those of us who see patients, the progressive memory complaints and clear-cut decline in function seen in those with drug-resistant epilepsy - particularly temporal lobe epilepsy - appear to sufficiently attest to the fact that the seizures are the culprit.

Of course, numerous other factors that might impact upon cognitive function in epilepsy. These include direct medication effects, the underlying cause of the epilepsy (e.g. head trauma), and depression, which is rampant in the epilepsy population. Critical as these may be in determining cognition, one would not expect these, for the most part, to have progressive effects; most underlying causes of epilepsy are not progressive, while depression's effects will vary over time even without treatment, and the impact of 
medication will be acute rather than cumulative.

But in the review which appears in this issue of the journal, Hamed presents a novel hypothesis, backed by considerable evidence, which points in a different direction: namely, that epilepsy is strongly associated with accelerated atherosclerosis, and that this chronic vascular disease, in turn, may lead to cognitive impairment over time in the epilepsy population. This notion and the prevailing view are hardly mutually exclusive; in fact, the effects of seizures and those of atherosclerosis could even be synergistic in impairing cognitive function.

But is it really true that epilepsy is associated with atherosclerosis? After all, to take the general contracting metaphor, we would not expect the wiring in a house to have an impact on the plumbing. Yet epidemiologic studies over several decades, from multiple populations, using slightly varying endpoints, clearly demonstrate that patients with epilepsy have significantly elevated rates of vascular disease ${ }^{4-8}$. That such vascular disease affects the brain is shown specifically in the elevated rates of stroke seen in several of these studies ${ }^{5,8,9}$. Reverse causation is an important confounder to keep in mind, as a fair fraction of epilepsy is caused by ischemic stroke. However, elevated rates of vascular disease are seen even in those with idiopathic epilepsy, and in those in whom a history of stroke has been specifically excluded ${ }^{5,9}$. Thus, this is not simply an artifact of stroke-induced epilepsy. Furthermore, an even more convincing set of studies has demonstrated that carotid intimal-medial thickness (CIMT) is significantly elevated in patients with epilepsy compared to controls ${ }^{10-12}$. This is noteworthy because CIMT is a powerful surrogate marker of atherogenesis; thus, this is rather strong evidence that the ischemic disease seen in this population is not due to hypercoagulable states, or hemodynamic derangements, but rather from atherosclerotic processes. And, as both the literature and common sense will tell you, the accumulation of such vascular disease in the brain should inevitably lead to cognitive decline.

Why might this be happening? Hamed reviews an extensive number of intermediate markers for vascular disease, each of which shows evidence of greater presence among the epilepsy population. One example is obesity, prominent among epilepsy patients, which can lead to the metabolic syndrome, diabetes, and vascular disease. Another category consists of the many serologic markers of vascular risk which are elevated in epilepsy patients, including serum lipids, liproprotein(a) $\{L p(a)\}$, homocysteine, C-reactive protein (CRP), and lipid oxidation products ${ }^{10,12}$.

Yet this only gets us part way down the causal chain, because if these alterations are the cause of chronic atherosclerosis in patients with seizures, the next crucial question is: what is it about epilepsy that gives rise to all these serologic derangements? One could conceive of factors related to the disease itself that might contribute to these phenomena, such as cellular inflammation, or alteration of the hypothalamic-pituitary axis. Such disease-mediated suggestions are purely speculative, without supporting evidence.

So here the editorialist will be more pointed than the author of the review in pointing the 
finger where the evidence strongly leads: toward the drugs. Abundant evidence has emerged in the last decade to indicate that the older antiepileptic drugs (AEDs), especially those which induce the cytochrome P450 system, are specifically associated with elevations in lipids, $\mathrm{Lp}(\mathrm{a}), \mathrm{CRP}$, and $\mathrm{HCY}^{13}$, with the evidence coming not just from cross-sectional studies, but from repeated-measures investigations which leave no doubt as to the causative role of the drugs ${ }^{14-16}$. CIMT too appears to be associated with the older drugs, and is greater with longer duration of exposure, consistent with a continuous accumulation process ${ }^{17}$. So if, indeed, the cognitive decline of epilepsy is atherogenic in nature, then the ultimate cause may well be the off-target effects of many of the drugs that physicians prescribe.

In a disease like epilepsy, in which almost everyone is treated, it can be hard to distinguish the effects of the disease from those of the drugs. But with the profusion of new agents over the last 20 years, we should now have the capacity to separate individual drug effects from the natural history of the disease. Doing so will be complex, however, and will require investigations of varying aims and designs. First, are the inducing AEDs associated with end-point vascular disease? Little study has been done of this issue ${ }^{9}$ and much more is needed. Then longitudinal follow-up studies will be need to address questions such as: how does the rate of cognitive decline in seizure-free patients with epilepsy compare to that of controls? If it is greater, does it correlate with atherosclerosis? And if so, does this in turn correlate with the use of enzyme-inducing rather than non-inducing AEDs?

These questions should keep us busy for a while, and will be crucial for prevention if some of this is disease- rather than drug-related (or, if it is drug-related, for those who are obliged to remain on the offending agents). In the meantime, we should keep in mind that there are many aspects of home maintenance, and we ill serve our patients if we fix their wiring only to gum up their plumbing.

1. Rausch, R. et al. Early and late cognitive changes following temporal lobe surgery for epilepsy. Neurology 60, 951-959 (2003).

2. Hermann, B. P. et al. Cognitive prognosis in chronic temporal lobe epilepsy. Ann Neurol 60, 80-87 (2006).

3. Lin, J. J., Mula, M. \& Hermann, B. P. Uncovering the neurobehavioural comorbidities of epilepsy over the lifespan. Lancet 380, 1180-1192 (2012).

4. Annegers, J. F., Hauser, W. A. \& Shirts, S. B. Heart disease mortality and morbidity in patients with epilepsy. Epilepsia 25, 699-704 (1984).

5. Ding, D. et al. Premature mortality in people with epilepsy in rural China: a prospective study. Lancet Neurol 5, 823-827 (2006).

6. $\mathrm{Mu}$, J. et al. Causes of death among people with convulsive epilepsy in rural West China. Neurology 77, 132 (2011).

7. Neligan, A. et al. The long-term risk of premature mortality in people with epilepsy. Brain 134, 388-395 (2011). 
8. Nilsson, L., Tomson, T., Farahmand, B. Y., Diwan, V. \& Persson, P. G. Cause-specific mortality in epilepsy: a cohort study of more than 9,000 patients once hospitalized for epilepsy. Epilepsia 38, 1062-1068 (1997).

9. Olesen, J. B. et al. Effects of epilepsy and selected antiepileptic drugs on risk of myocardial infarction, stroke, and death in patients with or without previous stroke: a nationwide cohort study. Pharmacoepidemiol Drug Saf 20, 964-971 (2011).

10. Hamed, S. A., Hamed, E. A., Hamdy, R. \& Nabeshima, T. Vascular risk factors and oxidative stress as independent predictors of asymptomatic atherosclerosis in adult patients with epilepsy. Epilepsy Res 74, 183-192 (2007).

11. Schwaninger, M. et al. Elevated plasma concentrations of lipoprotein(a) in medicated epileptic patients. Journal of Neurology 247, 687-690 (2000).

12. Tan, T. Y. et al. Long-term antiepileptic drug therapy contributes to the acceleration of atherosclerosis. Epilepsia 50, 1579-1586 (2009).

13. Lopinto-Khoury, C. \& Mintzer, S. Antiepileptic drugs and markers of vascular risk. Curr Treat Options Neurol 12, 300-308 (2010).

14. Mintzer, S. et al. Effects of antiepileptic drugs on lipids, homocysteine, and C-reactive protein. Ann Neurol 65, 448-456 (2009).

15. Mintzer, S. et al. Conversion from enzyme-inducing antiepileptic drugs to topiramate: Effects on lipids and c-reactive protein. Epilepsy Res 98, 88-93 (2012).

16. Bramswig, S., Sudhop, T., Luers, C., von Bergmann, K. \& Berthold, H. K. Lipoprotein(a) concentration increases during treatment with carbamazepine. Epilepsia 44, 457-460 (2003).

17. Chuang, Y. C. et al. Effects of long-term antiepileptic drug monotherapy on vascular risk factors and atherosclerosis. Epilepsia 53, 120-128 (2012). 